\title{
Can Early-Assignment Grades Predict Final Grades in IT Courses?
}

\section{Ms. Parameswari Ramanathan, Indiana University-Purdue University, Indianapolis}

Param Ramanathan works has a Senior Programmer Analyst for the Family and Social Services Administration (FSSA) IT division. She graduated from Pondicherry Engineering College, India with a Bachelors degree in Computer Science and Engineering. She then worked as a Software Engineer for Larsen and Toubro Infotech limited (L\&T), India for couple of years and then as a Senior Programmer Analyst for Indiana Support Enforcement Tracking System (ISETS), State of Indiana for few years. She then joined as a Senior IT Consultant at FedEx Corporation, Memphis, TN and worked in Accounts Receivables system for couple of years. At present, she is working for the Indiana Client Eligibility System (ICES), a FSSA IT division. She is currently attending Masters of Science degree in Computer and Information Technology at IUPUI University, IN. Her major concentration is Applied data analysis and management.

\section{Dr. Eugenia Fernandez, Indiana University-Purdue University, Indianapolis}

Eugenia Fernandez is an Associate Professor of Computer and Information Technology and Chair of the Department of Computer Information and Graphics Technology in the Purdue School of Engineering and Technology at Indiana University-Purdue University, Indianapolis. She is a Fellow of the Mack Center at Indiana University for Inquiry on Teaching and Learning and an Editor of the Journal of Scholarship of Teaching and Learning. Her research focuses on the scholarship of teaching and learning related to learning with technology. 


\section{Can Early Assignment Grades Predict Final Grade in IT Courses?}

\section{Introduction}

As colleges and universities are compelled to maintain good student retention and graduation rates, numerous research studies have been conducted to predict student's academic success. Most of the studies made in several educational institutions use predictors such as high school performance, American College Testing (ACT) scores and Scholastic Assessment Test (SAT) scores (Zwick \& Sklar, 2005; Delong, 1986; Jensen \& Barron, 2014; Roşeanu \& Drugaş, 2011) to determine the student academic performance. Educational institutions vary in their goals and hence these study results do not necessarily remain consistent or apply to other universities. Local institutional studies are essential.

Currently, the Computer and Information Technology program (CIT) at IUPUI has a grading system requirement which states that any grade lower than $\mathrm{C}$ in a course will not count as credit toward the degree and the student must retake the course. This program aims in achieving its goal to have the undergraduate students continue to make progress on their degree and eventually graduate on time. To aid in this process, the CIT program is interested in a way to predict a student's final course grade as early as possible to determine if student intervention is needed or if any change in educational strategies are needed.

At present, the extent to which early assignment grade helps predict the final course grade, and the relationship that is present between the two grades, is unknown. The purpose of this study is to investigate if the student's final course grade can be predicted based on the student's performance in the early graded assignments.

The grades obtained by a sample of CIT students in a variety of undergraduate courses will be considered for the research. The predictors, points earned in the first two graded assignments and the first test, will be used to examine the association between these and the final course grade.

This study results can be applied to CIT undergraduate program students to predict their final course grade. It will assist in identifying at-risk students who may underperform during the course so that the CIT educators and counselors can intervene and help these students to achieve better academic performance. This, in turn, will help students to graduate on time and to score better grades in each course they undertake.

\section{Literature Review}

In the past, several studies have been conducted to determine the factors that affect students' likelihood of persistence in higher education. Penn (1999) says maintaining enrollment is critical for a college's survival in the competitive higher education marketplace. Institutions face new challenges nowadays to keep the students enrolled until they earn their degrees. They constantly need to implement new effective and efficient strategies to improve retention, completion, and graduation rates. 
As the primary goal of every college or university is to maintain a high retention rate, these institutions do a lot of research on the reasons why college students leave college early. Anne (2010) states, "admissions officers consider high school grades and standardized test scores as the two primary factors in admissions decisions because research has demonstrated they are the two strongest predictors of student persistence in college" (p. ii). Her study results show that students with discrepant high school grades and standardized test scores had lower rates of persistence to the sophomore year and four-year graduation than those for students with nondiscrepant high school grades and standardized test. She concludes, "high school grades were found to be a stronger predictor than standardized test scores of both persistence to the sophomore year and four-year graduation” (p. 124). Likewise, Delong (1986) found that ACT scores play a major role in predicting grades in selected business courses. Her study showed that the students' academic performances can be predicted from prior performances.

These studies show that early academic performance helps predict the student's future performance. Jensen and Barron (2014) acknowledged "early academic indicators are strong predictors of course grades regardless of the level of the course, whether the classes are composed of majors or non-majors, or whether the course takes place at a liberal arts college or regional university" (p. 86).

Zwick and Sklar (2005) focused on other factors that play a role on students' college grades and degree completion such as student ethnicity and first language. Their analysis showed that high school GPA influenced the graduation of White/English students and the SAT score influenced the graduation of Hispanic/English students and White/English students.

Yet another study made by Sparkman (2008) examined the relationship between 15 subscales of emotional intelligence (self-regard, emotional self-awareness, assertiveness, independence, selfactualization, empathy, social responsibility, interpersonal relationship, reality testing, flexibility, problem solving, stress tolerance, impulse control, optimism, and happiness) and enrollment status, graduation status, and cumulative grade point average on traditional college students. He concluded "Social Responsibility was found to be the strongest positive predictor of graduation, followed by Impulse Control and Empathy while Flexibility proved to be a negative predictor of both enrollment and graduation" (p. iii). Similarly to studies mentioned above, Sparkman also found that "high school grade point average positively predicted enrollment, graduation, and cumulative college grade point average while ACT significantly predicted graduation and cumulative college grade point average" (p.iii). Within a related area, House (2000) studied the impact of students' self-beliefs and academic background on grade performance in Science, Engineering, and Mathematics (SEM) disciplines. He found these two factors to be significantly related to the grade performance of students in SEM majors.

Hunt (2011) studied potential predictors that impact student's developmental Math at public community and technical colleges. She categorized 13 potential predictors into three categories student characteristics, instructor characteristics and classroom characteristics. She found that ACT Math score, community college enrollment, and math pretest score were predictors of the elementary and intermediate algebra final exam score. 
On the contrary, Mattson (2007) study on understanding the pre-college variables and the success of at-risk students of a private research university revealed that SAT scores failed to predict the success score of college GPA. But pre-college variables, such as high school GPA, gender of student, and leadership experience prior to applying, were found to be highly significant predictors of college GPA. In a more focused study, Roşeanu and Drugaş (2011) likewise found that high school grade average was efficient in predicting academic performance of freshman psychology students at the University of Oradea.

From these research perspectives, it is obvious that the early academic results provide compelling hints about the future academic performance. Williford (2009) says "admissions practitioners as well as researchers generally understand that prior academic performance is the best available predictor of success in college" (p. 24). Although in the past, several studies have been conducted to determine overall student success and retention rate in higher education with predictors ranging along many different aspects, this study focused on a more granular level by focusing on the students' early performance within a course to predict the final course grade.

The main purpose of this study is to determine if the undergraduate students' early assignment grades in a course can help predict the final course grade. Jensen and Barron (2014) conducted a similar research study to predict final semester grades in Biology courses offered in a small liberal arts college and a regional state university. They found a strong correlation between the students' midterm exams grades and final course grade. Their study results showed that grades did not fluctuate throughout the semester, and if any changes occurred, were minimal. A similar study will be conducted with students enrolled in undergraduate Computer and Information Technology courses offered by IUPUI.

\section{Method}

Students enrolled in spring 2016 CIT undergraduate courses were used as the sampling frame for this study. Students enrolled in certificate-only courses and independent study courses were excluded. In spring 2016, there was a total of 1111 students in the sampling frame. A sample size of $10 \%$ of this population was considered to have sufficient statistical power to derive the results.

The stratified random sampling method was used to select the participants with the strata based on course level (e.g. 100, 200, 300 \& 400-level courses). The sample was randomly selected across the four strata so as to be proportional to the number of students enrolled in each stratum (course level). Table 1 shows the percentage of students selected from each course level resulting in the sample size of 111 . 
Table 1. Participant Sampling Plan

\begin{tabular}{|c|c|c|c|}
\hline $\begin{array}{c}\text { Course } \\
\text { Level }\end{array}$ & $\begin{array}{c}\text { Number of } \\
\text { Enrolled Students }\end{array}$ & Percentage & $\begin{array}{c}\text { Sample } \\
\text { Size }\end{array}$ \\
\hline 100 & 213 & $19 \%$ & 21 \\
\hline 200 & 537 & $46 \%$ & 51 \\
\hline 300 & 140 & $12 \%$ & 13 \\
\hline 400 & 221 & $23 \%$ & 26 \\
\hline Total & 1111 & & 111 \\
\hline
\end{tabular}

This study was conducted using existing student enrolment and grading information. Enrolment and demographic data - class standing and gender - was gathered from the university's Student Information System. Student grades were obtained from the Gradebook feature within the university's Learning Management System. The points earned and the points possible were recorded for the first and second assignments and the first test/exam in each course along with the student's final course grade. Institutional Review Board approval was obtained for this data collection.

As the point value of each assignment differed, they were normalized by converting to a percentage. To examine both a single score point and a cumulative score, the following percentages were computed: first assignment, second assignment, first and second assignment combined, and first test/exam. The resulting percentages were translated to a letter grade (A-F) using the common 90-80-70-60-and below scale. Plus/minus signs on the student's final course grade were ignored.

Regression and correlation were not options to determine if each resulting grade could predict the final course grade as the two variables were not independent of each other. Thus, each resulting grade was compared to the final grade and split into two categories as follows:

1. Final course grade is same or higher than assignment grade

2. Final course grade is lower than the assignment grade.

As we were looking for improvement in grades, cases in which the assignment grade and the final grade were both F's were placed into the second category. Chi-square goodness of fit tests were conducted using SPSS to determine if the number in each group differed from chance.

\section{Results}

Demographics of the resulting sample are provided in Table 2. 
Table 2. Sample Demographics

\begin{tabular}{|l|c|c|c|c|c|l|c|c|}
\hline \multicolumn{3}{|c|}{ Gender } & \multicolumn{3}{c|}{ Course Level } & \multicolumn{3}{c|}{ Class Standing* } \\
\hline & $\mathrm{N}$ & $\%$ & & $\mathrm{~N}$ & $\%$ & & $\mathrm{~N}$ & $\%$ \\
\hline \multirow{2}{*}{ Female } & \multirow{2}{*}{23} & 20.7 & 100 & 21 & 18.9 & Freshman & 8 & 7.2 \\
\cline { 4 - 9 } & \multirow{2}{*}{ Male } & \multirow{2}{*}{78} & 200 & 51 & 45.9 & Sophomore & 23 & 20.7 \\
\hline & & 300 & 13 & 11.7 & Junior & 33 & 29.7 \\
\hline & & 400 & 26 & 23.4 & Senior & 46 & 41.4 \\
\hline
\end{tabular}

Table 3 shows the percentage of students whose grades improved or declined at each checkpoint under study. Fifty percent of the student's grades did not change from the first test/exam to the final grade, and only $9 \%$ saw changes of more than one letter grade. Not all the changes were positive however. (Table 3). Frequency distributions relating each item to final grades are provided in Figure 1.

Table 3. Change in grades between first test/exam and final grade

\begin{tabular}{|l|r|}
\hline Change & Percent \\
\hline Improved by 2 letter grades & $3.0 \%$ \\
\hline Improved by 1 letter grade & $27.0 \%$ \\
\hline Unchanged & $50.0 \%$ \\
\hline Declined by 1 letter grade & $14.0 \%$ \\
\hline Declined by 2 letter grades & $3.0 \%$ \\
\hline Declined by 3 letter grades & $3.0 \%$ \\
\hline
\end{tabular}

Chi-square goodness of fit tests were conducted to determine if the proportion of the two categories for grades earned on assignment 1 , assignment 2 , combined assignments, and first test/exam were equal. Significant differences were found for the combined assignments and first test/exam. Results are provided in Table 4. As you can see from the results, the percentage of students whose grade stayed the same or improved was fairly consistent for assignment 1 and 2 , increased a bit on the combined assignments, and was significantly higher for the first test/exam. 


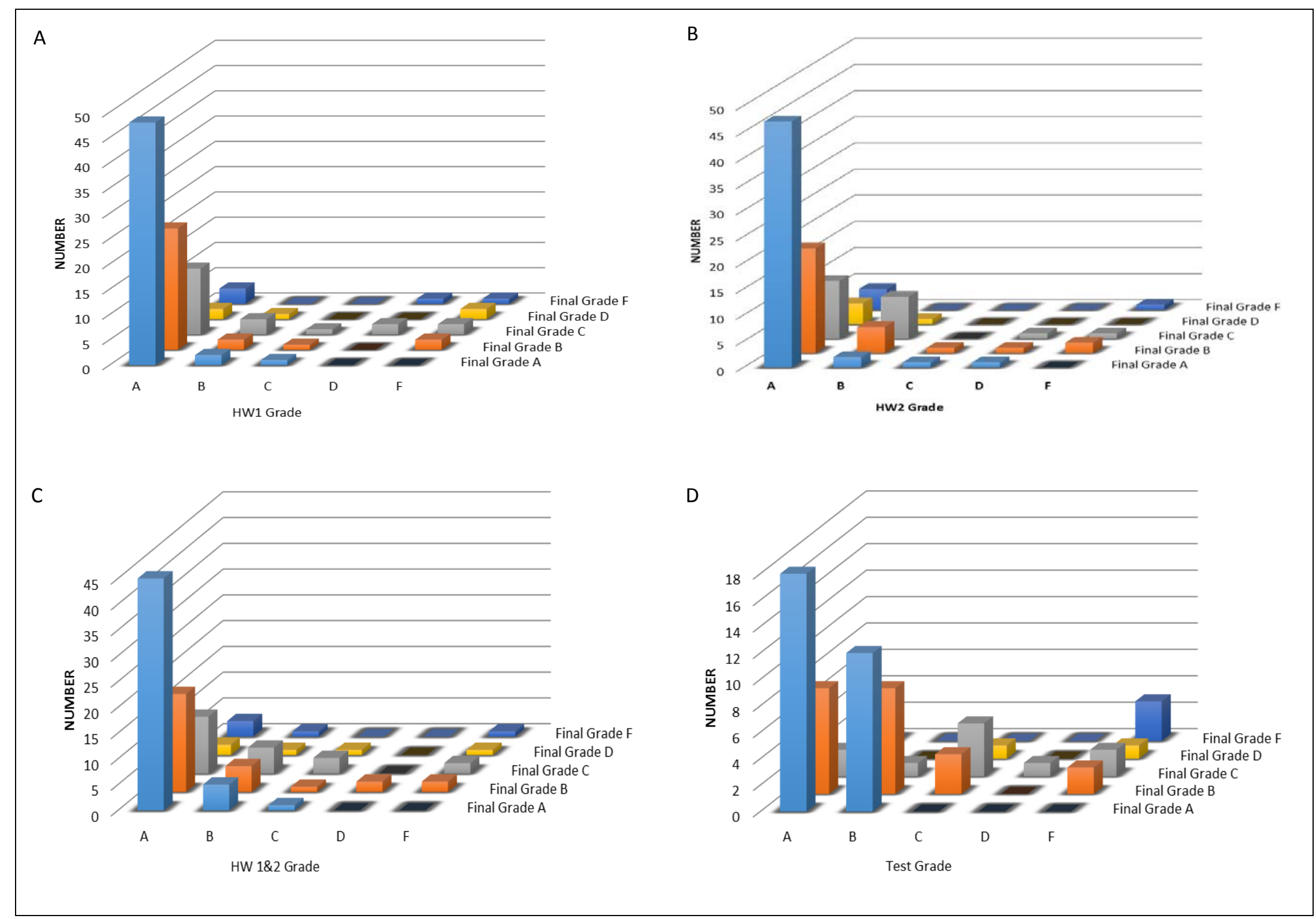

Figure 1. Correlation of student's final grade with Assignment 1 (A), Assignment 2 (B), combined assignments (C) and first test/exam grades (D). 
Table 4. Results of Chi-square Goodness of Fit Test Comparing Proportion of Final Grade Equal to or Higher than Variable Grade Against Chance

\begin{tabular}{|l|c|c|c|lll|}
\hline Variable & $\mathrm{N}$ & $\chi^{2}$ & Sig. & \multicolumn{3}{|c|}{ Observed Values } \\
\hline Assignment 1 & 111 & 2.03 & .155 & $\begin{array}{l}\text { Same or Better Grade } \\
\text { Lower Grade }\end{array}$ & $\begin{array}{l}63 \\
48\end{array}$ & $\begin{array}{l}56.8 \% \\
43.2 \%\end{array}$ \\
\hline Assignment 2 & 111 & 1.52 & .217 & $\begin{array}{l}\text { Same or Better Grade } \\
\text { Lower Grade }\end{array}$ & $\begin{array}{r}62 \\
49\end{array}$ & $\begin{array}{l}55.9 \% \\
44.1 \%\end{array}$ \\
\hline $\begin{array}{l}\text { Combined } \\
\text { Assignments }\end{array}$ & 111 & 4.77 & $\mathbf{. 0 2 9}$ & $\begin{array}{l}\text { Same or Better Grade } \\
\text { Lower Grade }\end{array}$ & $\begin{array}{l}67 \\
44\end{array}$ & $\begin{array}{l}60.4 \% \\
39.6 \%\end{array}$ \\
\hline First Test/Exam & 66 & 19.6 & $\mathbf{. 0 0 0}$ & $\begin{array}{l}\text { Same or Better Grade } \\
\text { Lower Grade }\end{array}$ & $\begin{array}{l}51 \\
15\end{array}$ & $\begin{array}{l}77.3 \% \\
22.7 \%\end{array}$ \\
\hline
\end{tabular}

To investigate how the combined assignments and first test/exam could be used to identify at risk students, we calculated the mean and median for each category of students. Results are shown in Tables 5 and 6.

To examine if there were any differences between the first test/exam category by gender, course level or class standing, chi-square tests of independence were calculated for each of the demographic factors. No significant differences were found.

Table 5. Mean, Median and Distribution for each Category for Combined Assignments

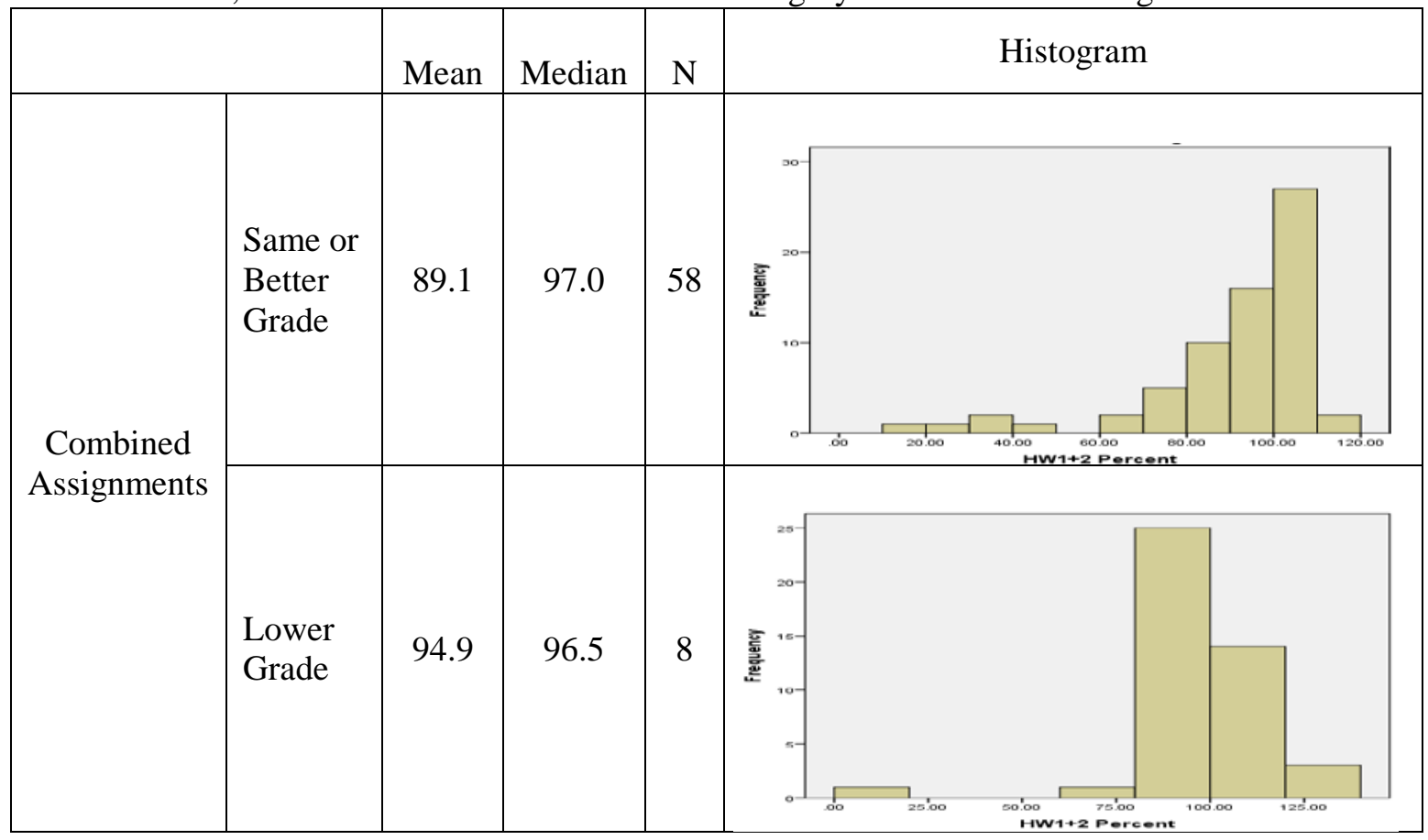


Table 6. Mean, Median and Distribution for each Category for First Test/Exam

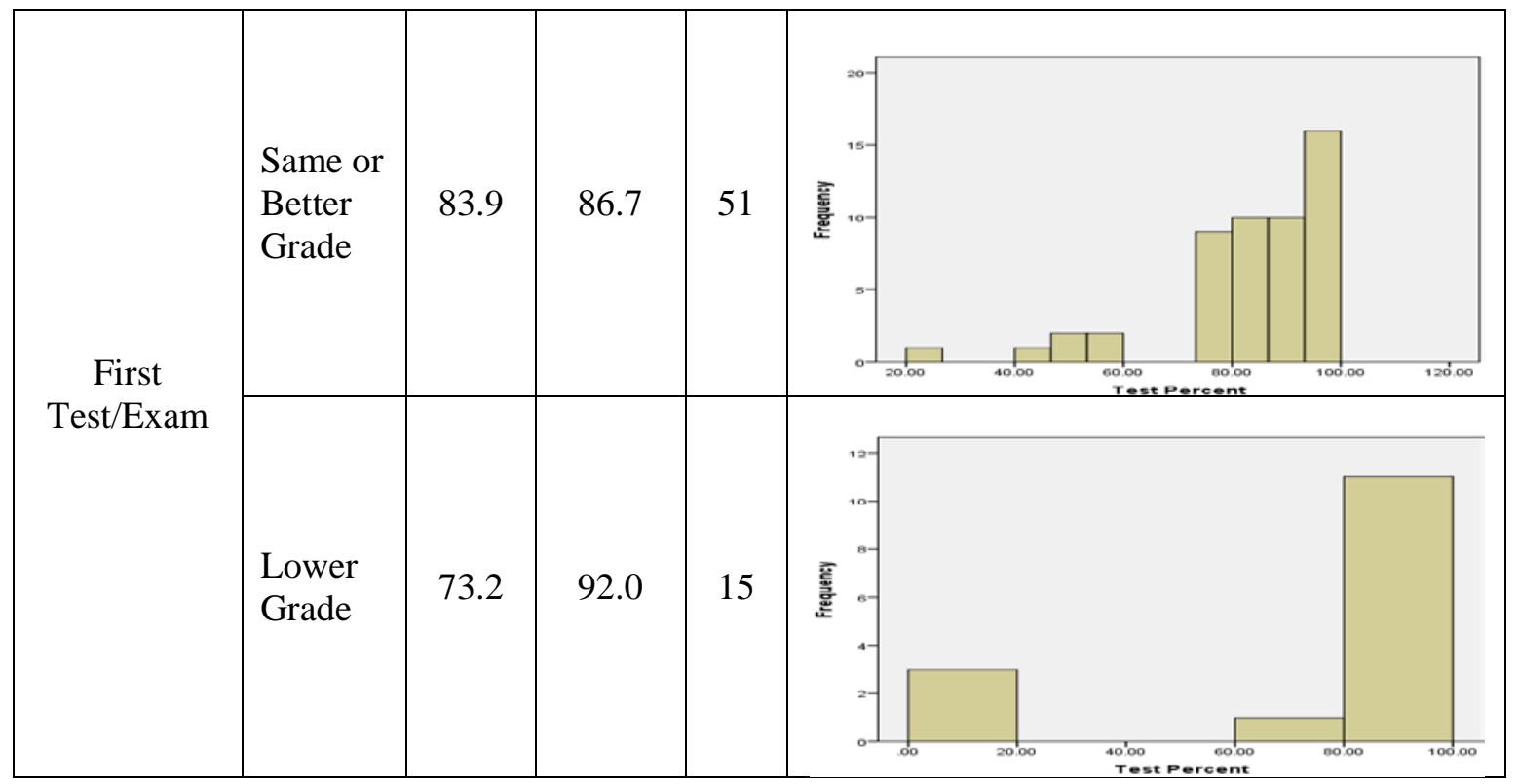

\section{Discussion}

The primary objective of this study was to examine if early assignment grades predict the final course grade. More specifically, the study investigated if the percentage of students whose final course grade was the same or better than the item investigated was statistically different from the percentage of students whose final course grade was below the item grade.

The findings show that the combination of the first two assignments was a significant predictor of the final course grade. However, the information in Table 4 for the combined assignments shows a highly right skewed distribution for the grades of students whose final grade declined, with a mean higher than those of students whose final grade did not decline. We surmise that this group shows students who did well on the assignments but whose later performance was not good. Given the relatively low point value for the assignments (80.2\% worth 60 points or less), this is not surprising. Because of this variation, it would be difficult to use the combined assignments as a way to identify students at risk of failure. Failure for the CIT program is defined as a grade less than $\mathrm{C}$ since that means the student must repeat the course.

The findings also show the first test/exam as a significant predictor for the final course grade. This is similar to the results of Jensen and Barron's (2014) work which concluded that midterm exam grades are strong predictors of the final course grade in Biology courses. This is not surprising as tests/exams tend to comprise a larger percentage weight of the final course grade. Thus it is possible to use the first test/exam as an indicator for poor performance.

However, this study's purpose was to discover an early predictor of final course grades so that an intervention might be used to help students perform better. $92.4 \%$ of the first test/exams in this study took place in week seven of the semester and later, similar to the midterm timing of Jensen 
and Barron (2014). Alas, this study revealed that the earlier assignment grades were not good predictors of the final course grade.

Given our findings, students who score low grades ( $\mathrm{C}$ or below) in the first test/exam are most likely to earn the same low final course grade. So while it is possible to use the first test/exam grade to identify at-risk students and intervene to help them, midterm and beyond may be too late. According to Kuh (2005),

It is too late to wait until midterm exam time to give students an idea of how well they are performing. ...the system simply cannot respond quickly enough to help student salvage a poor semester if they need to wait until well beyond the midpoint of the semester before someone contacts them to formally suggest they need immediate attention to their academic work. (p.103)

The earlier the first test/exam grades are assessed, the sooner the at-risk students can be identified and helped. Thus the next step in this line of research will be to determine if an early test/exam continues to be a good predictor of final course grade. Plans for this study are underway and the faculty involved have agreed to give a test/exam by the fourth week of the semester. Similar analysis will be conducted.

If the earlier test/exam is found to be a good predictor of final grades, the next step will be to use this predictor to identify at risk students, provide an intervention, and examine if any changes result. Anecdotal evidence at IUPUI has shown that class attendance coupled with performance on early assignments can also indicate final course performance. This would also be an area to study more formally.

In conclusion, the results of this study hold interesting and challenging possibilities which would be of interest to many educators, counselors, and students.

\section{References}

Anne, E. (2010). An examination of the likelihood of persistence of students with discrepant high school grades and standardized test scores. (Doctoral dissertation). University of Alabama, Alabama. Retrieved from http://libcontent1.lib.ua.edu/content/u0015/0000001/0000385/ u0015_0000001_0000385.pdf

Delong, G. (1986). The predictive value of ACT scores in determining grades in selected business courses. (Doctoral dissertation). Oklahoma State University.

House, D. J. (2000). Academic background and self-beliefs as predictors of student grade performance in science, engineering, and mathematics. International Journal of Instructional Media, 27(2), 207-220.

Hunt, D. L. (2011). Predictors of student outcomes in developmental Math at a public community and technical college. (Doctoral dissertation). Marshall University, West Virginia. Retrieved from Marshall Digital Scholar, http://mds.marshall.edu/etd/42/. 
Jensen, A. P, Barron, N. J. (2014). Midterm and first-exam grades predict final grades in biology courses. Journal of College Science Teaching, 44(2), 82-89.

Kuh, G. D. (2005). Student engagement in the first year of college. In M.L. Upcraft, J.N. Gardner, \& B.O. Barefoot (Eds.), Challenging and supporting the first-year student: A handbook for improving the first year of college (pp.86-107). Indianapolis, IN: Jossey-Bass.

Mattson. E. A. (2007). Beyond Admission: Understanding pre-college variables and the success of at-risk students. Journal of College Admission, (196), 8-13.

Penn, G. (1999). Enrollment management for the 21st Century: Institutional goals, accountability, and fiscal responsibility. ASHE-ERIC Higher Education Report, 26(7).

Roşeanu, G, Drugaş, M. (2011). The admission criteria to the university as predictors for academic performance: A pilot study. Journal of Psychological and Educational Research, 19(2), 7-19.

Sparkman A. L. (2008). Emotional intelligence as a non-traditional predictor of college student retention and graduation. (Doctoral dissertation). University of Southern Mississippi, Mississippi. Retrieved from Dissertation Archive, Paper 822 at http://aquila.usm.edu/ theses_dissertations/822

Williford, A. M. (2009). Secondary school course grades and success in college. College and University, 85(1), 22-33.

Zwick, R., \& Sklar, J. C. (2005). Predicting college grades and degree completion using high school grades and SAT scores: The role of student ethnicity and first language. American Educational Research Journal, 42, 439-464. doi: 10.3102/00028312042003439. 